ARTICLE

\title{
How does watching YouTube fashion content impact perception of appearance: a phenomenological study of Korean women in Generation Z
}

\author{
Juha Park (iD ${ }^{1} \&$ Jaehoon Chun (iD) ${ }^{1 凶}$
}

Generation Z grew up in a media-friendly environment, and this study aimed to examine how YouTube influences their perception of appearance. The research followed the methodological procedures of Giorgi's phenomenology and conducted in-depth interviews of 15 Korean women who were born between 1995 and 2005 and enjoyed watching fashion-related YouTube content. The results showed that Generation Z was greatly influenced by fashion YouTubers and the visual stimuli they provided. They had a positive attitude towards YouTubers, actively participated in online non-face-to-face communication and tried to look like them. Their watching of YouTube fashion content had a variety of influences with regard to their perception of looks and appearance management. Repeated exposure to YouTubers' slim bodies and appearance-related content led viewers to accept this body type as the ideal. Moreover, appearance-related information provided by YouTubers was being used as indexes of their lifestyles and consumption habits. Though YouTubers' influence was both positive and negative, Generation Z's pursuit of their own personalities made YouTube an independent fashion medium that was not affected by space or time.

\footnotetext{
${ }^{1}$ Department of Textiles, Merchandising and Fashion Design, Seoul National University, Seoul, Republic of Korea. ${ }^{凶}$ email: kingkem2@snu.ac.kr
} 


\section{Introduction}

eneration $\mathrm{Z}$ is growing up alongside the development of high-tech mobile devices, which they use to achieve their multiple purposes (Southgate, 2017). They are rising as a new social power and main consumers in the global market with their simultaneous pursuit of information and fun, while sharing their experiences with others on social networks or watching videos produced by YouTubers (Hasnan, 2019). They are not only interested in appearance management, dieting and exercising but also in fashion and shopping to express their identity (Pastore, 2020). Compared to other generations, they are a generation that actively participates in live streaming and chatting on YouTube (Park, 2019) and is most influenced by information provided by influencers on YouTube than by entertainers (Mullen, 2019). Generation $Z$ acquires information from social media platforms and share it with others, thereby producing a new kind of information. We need to pay attention to the fact that they are affected by influencers on social media platforms; these influencers are a new type of celebrities, and Generation $\mathrm{Z}$ shares stronger bonds with them than with celebrities in traditional media (Tran and Strutton, 2014) and tend to perceive their information as more authentic (Stefanone et al., 2010; Wiley, 2014). According to Choi and Behm-Morawitz (2017), YouTube viewers have more confidence in the video content of YouTubers if they are attractive. However, we cannot overlook the influence of social media and how it makes women dissatisfied with their body and how they look (Fardouly and Vartanian, 2015). There is a positive correlation between exposure to ideal images on social media and physical dissatisfaction in young women (Tamplin et al., 2018). The media portrayals of the ideal appearance negatively impact women's perception of body image or mood more than it does young men (Perloff, 2014).

Hence, the purpose of this study is to examine the influence of YouTube on Generation $\mathrm{Z}$ with regard to their perception of looks and their appearance management behaviour. This study is significant because it expands our academic understanding of Generation Z, highlights the place of YouTube as a new medium for Generation $Z$ and examines fashion-related YouTube content. Moreover, because YouTube influences the general lifestyle and consumption behaviour of Generation $Z$, it is expected that research on the media uses of this generation will contribute to the development of the fashion industry to better target the new generation. Most previous studies analysed the effects of printed or traditional media and TV celebrities rather than the YouTube platform, which is now attracting attention. A few studies have shed light on the YouTube platform, which actively utilised by Generation Z, and on the consumption of very popular fashionrelated content. It is expected that videos on physical charm and looks created by YouTube fashion influencers and their communicative modes will have various effects on watching YouTube fashion content and the appearance management behaviour of Generation Z.

\section{Literature review}

Conceptualisation and characteristics of Generation Z. Generation $\mathrm{Z}$, which is recently attracting attention, refers to the generation born between 1995 and 2005. There is a general agreement that Generation Z appeared in 1995 (Berkup, 2014; Adecco, 2015; Priporas et al., 2017), but some say they appeared in 2000 when they began to attract attention (Bennett et al., 2012; Ozkan and Solmaz, 2015). Bearing in mind the opinion of a lot of scholars and the fact that Generation Y, who came immediately before Generation Z, is regarded as people who were born before 1995-1994 latest (Morton, 2002), this research defined Generation $\mathrm{Z}$ as those born between 1995 and 2005. They are referred to as 'Generation Z', corresponding to the last letter of the alphabet. According to Chicca and Shellenbarger (2018), as the generation that widely absorbs digital culture, Generation $\mathrm{Z}$ has a strong individualistic tendency to pursue practicality based on their satisfaction and tastes and, in general, is sceptical about external information and advertisements. Based on several recent reports, papers, articles, and books about the characteristics of Generation Z, they can be deduced to have three defining characteristics.

First, Generation $\mathrm{Z}$ is considered to be the digital generation because of their active and native-speaker use of digital content (Wiedmer, 2015). Unlike the millennial generation that encountered digital media as they grew up, Generation $\mathrm{Z}$ was raised during a marketing flood of digital devices. They became familiar with devices like TVs, computers, tablet PCs and smartphones as soon as they were born, often using five screens at the same time (Lypnytska, 2019). Southgate (2017) notes that there is a steady decline in the rate at which Generation $\mathrm{Z}$ watch TV, read books and listen to the radio while there is a significant increase in the amount of time spent on mobile devices. They created the 'influencer culture' with their interactions with social media celebrities (Paton et al., 2019) and regard mobile devices as their major tool for cultural media production and as a space to play. The use of various social network platforms on mobile phones has become an integral part of Generations Z's daily lives (Ozkan and Solmaz, 2015). Generation $Z$ has something in common with Generation Y (millennials)-born between 1980 and 1994-in that they are both familiar with mobile devices. However, previous studies show that Generations $\mathrm{Y}$ and $\mathrm{Z}$ differ in many aspects (Adecco, 2015; Bolser and Gosciej, 2015). For example, a comparison of the two generations shows that Generation $\mathrm{Z}$ is better at multitasking, processing information, productivity and accessing information in a digital space (Adecco, 2015). Furthermore, in terms of social media use, they are more active than other generations, replacing face-to-face relations with media interactions (Lidija et al., 2017). Generation Z pursues both information and fun simultaneously, while sharing their experiences with others on social networks or watching videos produced by YouTubers (Hasnan, 2019). Accordingly, they are heavily influenced by newly rising YouTube celebrities in the field of fashion, beauty, lifestyle and purchase behaviour (Djafarova and Rushworth, 2017; Kim et al., 2018). They are constantly sharing something on the Internet and social media networks with friends and acquaintances, a situation that can engender social media addiction (Berkup, 2014).

Second, despite the fact that they are skilled at non-face-to-face interactions where they share information and opinions with others online, Generation $\mathrm{Z}$ shows project an image of isolation from others. Excessive exposure to technology can make them anti-social or unstable and cause mental health problems due to their weak concentration abilities (Singh and Dangmei, 2016; Chicca and Shellenbarger, 2018). $\mathrm{Na}$ (2018) regards this as the manifestation of an individualistic tendency, unique to Generation $\mathrm{Z}$. While they form a group when sharing common concerns and tastes online, they scatter easily. Therefore, it can be said that Generation $\mathrm{Z}$ is inclined to pursue discontinuous and immediate ties rather than continual relations with others though they actively engage in relatively free non-face-to-face relations online (Daehaknaeil20s Lab, 2018).

Third, Generation Z pursues individuality (Singh and Dangmei, 2016), wishes to differentiate themselves from others and is extremely self-confident (Adecco, 2015; Lorgulescu, 2016). The Korean Generation $\mathrm{Z}$ is interested in leisure activities like gaming, going to the movies and shopping but invest their allowances in taking care of their appearance in a bid to 'show off in front of 
others (Park, 2017). They are very interested in appearance management activities, such as fashion and beauty (Lee, 2019a) and acquire related and relevant information from social media platforms. This generation uses smartphones on a daily basis, actively searching for and purchasing inexpensive products online (Paton et al., 2019).

As such, the fact that this generation maintains and expands non-face-to-face relations based on active online communication and tastes can be interpreted as a new cultural behaviour. Furthermore, Generation $\mathrm{Z}$ places emphasis on appearance management and individuality, implying that their characteristic behaviour of watching YouTube fashion videos makes them different from other generations.

YouTube and fashion content. As a video content sharing site, YouTube, which has developed rapidly since its creation in 2005, is a media platform that allows one to upload, watch and share videos with others (Linkletter et al., 2010). YouTube is growing based on young users including Generation Z (Kemper, 2019). It produces and promotes various user-centred content, such as films, TV programmes, news reports and commercials, as it is a site where videos can be uploaded and shared easily without special limitations (PR Newswire, 2019). As a result, it is possible for YouTube video producers to promote their own channels, for users to exchange feedback via videos (Tang et al., 2012) and for viewers with similar concerns to engage in open exchanges by expressing their 'likes', real-time comments, interacting through chat windows and sharing videos with others. Beyond providing a large amount of information, YouTube allows people to share their opinions and stories, and it serves as a source of entertainment (Freeman and Chapman, 2007), improving on the shortcomings of text-based social media in many ways.

Fashion-related content on YouTube not only provide viewers with a variety of themes, such as fashion goods, fashion trends and fashion marketing, but satisfy the needs of consumers by reflecting rapidly changing fashion trends. Particularly, subscription to fashion videos are based on viewers' tastes, appearance and fashion. Thus, the ideal image of a YouTuber is as an informant and the content of their videos can affect viewers' perceptions (Patrick et al., 2004). The images and visual effects provided by fashion YouTubers, alongside their unique appearance, diction and expressions help explain fashion styles or appearance management. These draw attention to the fashion YouTubers.

Korea is the market with the highest rate of YouTube content consumption (Byun, 2018). The main concerns of Generation Z are related to appearance management issues, such as fashion and beauty, as well as leisure activities such as gaming, films and shopping (Lee, 2019b). Moreover, YouTube fashion channels on looks and specific tastes are very popular with young people. Hence, if we examine the content of YouTube fashion videos, the manner in which the main viewers consume YouTube contents, and the resulting change in viewers' perception and behaviour, we will have a better understanding of the media culture of the new generation.

Influence of social media on appearance management. Studies on the effects of the media on viewers' perception of looks and appearance management behaviour have mainly focused on TV or magazines, regarded as traditional media types (Meier and Gray, 2014). However, the popularity of printed media such as magazines has declined among young women, while the consumption of image-based information has increased on social media (Bell and Dittmar, 2011). The biggest difference between traditional media (print or televised media) and social media is that anyone can be a producer and share the content for free. Also, it is possible to form intimate relationships through online non-face-to-face interaction with other social media users (Tiggemann and Zinoviev, 2019). According to a previous study that analysed the effect of media type on appearance dissatisfaction in young women, media exposure is linked to women's dissatisfaction with their bodies and increased investment of time or money in the ideal appearance/body. Most social media influencers as producers of appearance-related content are generally slim (Grabe et al., 2008). Also, the study of the influence of young and rich influencers on social media shows that they connect with followers by sharing YouTube content on luxury lifestyles and daily appearance management. These content make it easy to form homogeneousness with influencers because daily-created fashion-related content are more relatable for young female viewers (Abidin, 2016). Furthermore, it is possible to form intimate relationships due to the selective information on YouTube and interacting with followers or influencers using verbal/nonverbal communication, which have various effects on viewers' body dissatisfaction (Grabe et al., 2008). The portrayal of women with the ideal body on YouTube contributes to social comparison of viewers' appearance on a daily basis (Myers and Crowther, 2009). Moreover, Keum (2006) asserts that Generation Z's frequent use of smartphones has led to active use of social media platforms, and that the body images presented by YouTubers form a standard that viewers compare their own body image to.

In the last 10 years, a new consumption culture, which involves acquiring information from YouTube rather than from traditional media such as TV, radio and magazines, has been established (Herold, 2008). YouTube is easy to use and provides seamless access to user-based content (Lee and Watkins, 2016). In addition, YouTubers also engage in two-way communication, which allows subscribers or fans to catch a glimpse of their private lives (Stever and Lawson, 2013). Though their content is produced by advertisers, YouTubers are perceived as consumers, similar to viewers and unlike celebrities on TV. Thus, the communication between an influencer and a viewer is assumed to be authentic and reliable (Veirman et al., 2017). As a result, information producers on social media influence numerous people through indirect relations with 'followers' in various complex manners (Gladwell, 2000). Accordingly, YouTube influencers play an important role in the fashion industry (Wiedman et al., 2010). Viewers feel that they will receive positive feedback on their appearances if they copy celebrities' lifestyles (Djafarova and Rushworth, 2017) and learn and practice the appearance management behaviour of their favourite celebrities.

Previous studies found that viewers used to receive information on appearance management through traditional media in a oneway manner in the past. However, YouTube influencers deliver intimate information about their personal and daily life to viewers and communicate with them actively. This can have a variety of effects on Generation Z, who are active in online communities and are very interested in appearance management.

\section{Method}

Regarding the research methodology, a review of literature and in-depth semi-structured one-on-one interviews were conducted. First, the literature review identified the characteristics of Generation $\mathrm{Z}$ and the YouTube environment. Next, a questionnaire was devised for in-depth interviews based on the literature review, which dealt with the effect of media on the perception of looks and appearance management behaviour. The reason for using this research methodology is that interviews are a common method to collect people's perception of body images, their emotional experiences about a body and how to interpret data collected 
Table 1 Description of participants $(N=15)$.

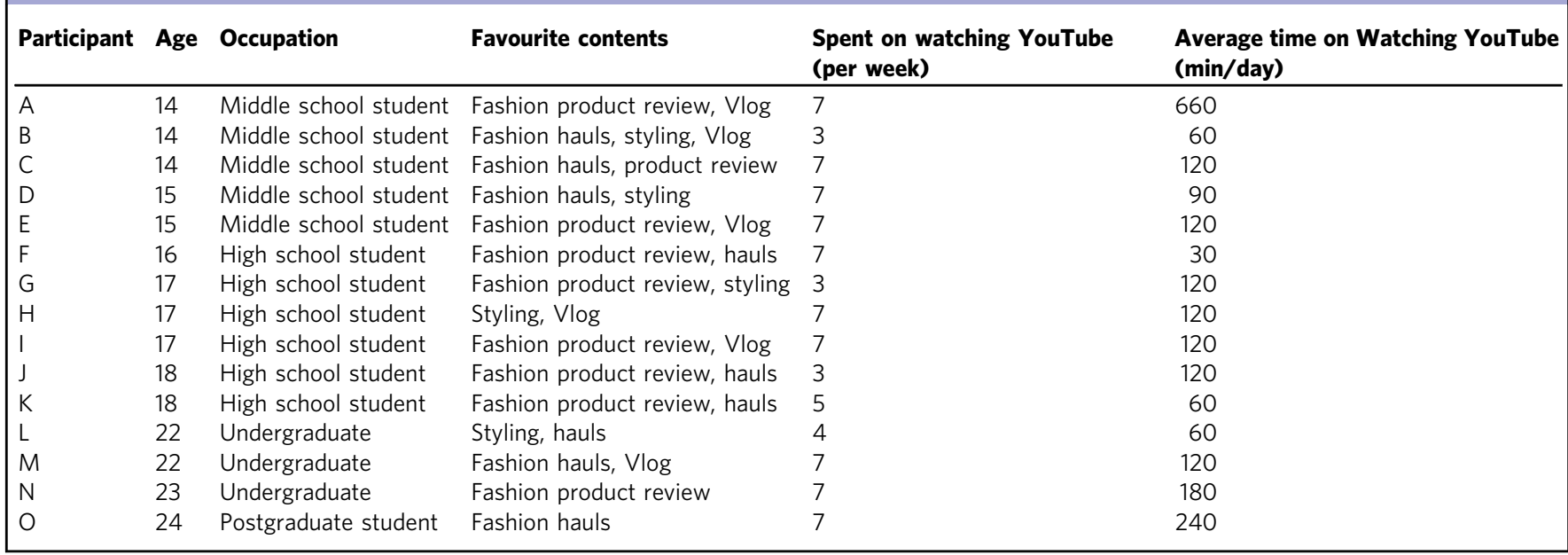

(Berry et al., 2010; Snoböhm et al., 2010; Jensen et al., 2014). The study was approved by the Institutional Review Board for participant recruitment and research procedures. The interview participants consisted of 15 Korean women in Generation $\mathrm{Z}$ born between 1995 and 2005 (as of 2019, those aged between 14 and 24). Based on previous studies and the latest trend that Generation $\mathrm{Z}$ was consuming a lot of fashion-related YouTube content, this study assumed that young Korean women in Generation $\mathrm{Z}$ were influenced by media through frequent watching of YouTube videos than other printed media, given that they were highly interested in many aspects of appearance management, including fashion, beauty and dieting. Hence, the study recruited Generation $\mathrm{Z}$ women who watched fashion videos that cover introductions and reviews of fashion goods, fashion coordination, fashion hauls, fashion trends/knowhow and everyday fashion more than three times a week on YouTube and/or Instagram (Table 1).

Through interviews with participants, the study surveyed general perception of appearances, including interest in and satisfaction with appearance management, and investigated the viewing frequency of YouTube fashion content, the types of content watched and favourite videos. The study found that the most enjoyed YouTube fashion content are fashion product reviews, hauls and styling. It also found that the participants spend an average of 5.8 days a week on the YouTube platform and $2 \mathrm{~h}$ and $30 \mathrm{~min}$ a day watching fashion-related content. Questions were asked about attitudes to media, including feelings and perception about YouTubers, and an analysis conducted of perceptions formed after watching YouTube fashion videos on specific aspects of appearance management behaviour, including facial/body care and fashion styling.

The study employed the methodological procedures of Giorgi's (1994) phenomenology to interpret the research findings. Our four-step data analysis procedure as proposed by Giorgi is as follows: statements by participants were transcribed to Micro Software, and repetitive readings of stated data were conducted to acquire sufficient knowledge about and understanding of all particulars mentioned by the participants. Next, the transcript was re-read to identify spontaneous shifts in meaning with respect to the participants' experiences of the phenomenon. At the core of the second phase, meanings inherent in the data were derived and the contents described were then classified into meaning units. In other words, the research underlined meaningful words or sentences from participants' responses and then put them in meaning units. For instance, if a participant's response after watching a video is 'I see and copy almost everything from YouTube', 'Everything is possible if you can have plastic surgery', certain words and sentences are highlighted and classified into meaning units. We extracted phrases that directly relate to the phenomenon under investigation, such as the participants' specific use of media experiences and perception of their appearance and bodies. Third, we attempted to glean participants' experiences from various perspectives through conversions of statements of integrated meaning units into academic language. This process aimed to increase the connection with the research theme by categorising subthemes to structural themes (Jensen et al., 2014). In the final step, after understanding what participants' statements mean for this research, textural subthemes from meaning units were integrated into coherent statements. We also emphasised the meaning of experiences through interpretive and reflective writings (Kim and Jung, 2017).

Findings. The general media usage of the participants were examined, including when and why they watch YouTube fashion content as well as the content and characteristics of the content they watch.

The research findings show that most participants never or rarely watched TV because they can watch TV programmes on YouTube. They said that they see YouTube as an efficient medium because they can spend their spare time alone, summarise and immediately watch important parts only through their mobile phones, and that information search through YouTube is unlimited in terms of space and time. Moreover, fashion information can be uploaded faster than on other media platforms. They also get notifications to watch newly uploaded videos by YouTubers' whose channel they are subscribed to. This is especially so for the teenage participants who spend their spare time watching as much YouTube videos as possible. They access YouTube habitually in addition to searching for information and describe it as similar to turning on a TV or watching the drama played out by other viewers. The findings also showed a high usage rate of the YouTube app by the participants, which proved that watching YouTube videos on a mobile phone has replaced the TV as a daily activity as the platform is not limited by space or time. In the end, Generation $\mathrm{Z}$ considers watching YouTube as a hobby, leisurely activity and a quick way to acquire information.

Some Generation $\mathrm{Z}$ viewers are subscribed to certain YouTube channels and actively participate in online non-face-to-face communications, including sharing of their opinions and ideas, 
chatting and commenting. They band together and have a sense of belonging pursuing non-face-to-face interactions. In addition, they attempt to imitate the external attractions of a YouTuber while following the YouTuber's Social network service account, give favourable comments, ask for product information and copy what they see. With regard to the phenomenon of 'fandom' where individuals follow certain celebrities and pursue interactions with them, Johnson notes that fans form their selves and embody their identities by aligning themselves with a celebrity who is similar to themselves and one who has intimacy and values they share (Seok and Cho, 2016). In other words, Generation Z's spontaneously viewing and copying a YouTube video can be viewed as attempts to show/define their identity by sharing experiences with a group to which they belong on social media.

The participants' YouTube fashion content viewership experiences were expressed in a manner from which eight structural themes were drawn from several subthemes. These were clustered and analysed with the aim of describing the themes and the essence of the phenomenon. The findings are as follows: feelings about YouTubers, effects of YouTube fashion content on perceptions of looks and appearance management behaviour of viewers. Examples of structural themes and textural subthemes are shown in Table 2.

\section{Perception and feelings about fashion YouTubers}

Perceptions of fashion YouTubers' appeal. The study examined the participants' general perception of the appeal of fashion YouTubers and assessed their emotional reaction to the reliability of information YouTubers provide and the formation of bonds. Previous study found that viewers copy the appearance management routines provided by beauty YouTubers (Choi and Behm-Morawitz, 2017). This is especially so for teenagers who are highly interested in how they look and are more influenced by specific and visual cues such as clothing than by abstract cues from celebrities they see in the media (Ryan, 1966).

We deduced from the interviews that the research participants do not just want to look like the fashion YouTubers, but also want to emulate their behaviour, habits and values. Unlike traditional celebrities, YouTubers are regarded as honest, natural, friendly and attractive. Furthermore, teenagers attach great importance to the sexual attraction of fashion YouTubers and value this physical attraction more than internal characteristics like personality and values. The participants cited specific body parts of a YouTuber, including the eyes, legs and waist, and reported that they were attractive because they (YouTubers) look like their ideal beauty.

[She] has a really nice body. It's her attraction. If Ryu's Penna has a slender waist, it's all the better. I say a wasp waist. In particular, her legs are most charming so I want a look like her. She has very long and thin legs and also a slim waist. (B, Middle school student, 14 years old)

Trust in information by fashion YouTubers. With regard to the reliability of the information provided by fashion YouTubers, every participant reported that the fashion YouTubers they watch have internal and external attractions or that they had purchased fashion goods or followed the appearance management methods introduced by the YouTubers. According to previous studies, Generation $\mathrm{Z}$ respects others by never doing what others do not want (Singh and Dangmei, 2016; Daehaknaeil20s Lab, 2018). Although Generation $\mathrm{Z}$ is skilled at non-face-to-face interactions where they share information and opinions with others online, they do not see themselves as simple viewers or consumers who just browse for product information. They instead demand a real

\section{Table 2 Structural themes and textural subthemes.}

\section{Structural themes}

Perception and feeling about fashion YouTubers

Affection for physical and inner beauty

Suspicion of advertising and partial trust

Non-face-to-face bonds

The effects of YouTube fashion content on perception of looks

Formation of an ideal body image and increased

surveillance of self

Acceptance/rejection of the diversity of face or body

Pursue their own individuality

The effects of YouTube fashion content on appearance management behaviour

Following YouTubers' appearance management

Search for fashion goods based on the viewers' taste

\section{Textural subthemes}

- Feeling affection for YouTuber's physical or fancy style

- Expert information about fashion

- Positive behaviour, attitude, habits, values of YouTubers

- Teenagers are especially interested in appearance/sexual appeal of YouTubers

- Generally trust the products YouTubers introduce and agree with their opinions

- YouTubers are regarded as honest, natural, friendly and attractive

- Scepticism about TV celebrities, avoid intended advertisement

- Friendly explanation of everyday appearance management

- Similar lifestyle and age, common experiences, personal story

- Preferred distance from YouTuber (don't want to be a friends in reality)

- Direct appearance and body related social comparison with YouTubers

- Active acceptance of YouTubers' opinion about appearance

- Upward comparison of social status with YouTubers

- Satisfaction with appearance and emphasis on individuality

- Separation of ideal and beauty in reality (I can understand diversity in appearance on YouTube but I can't be like that)

- Recognising YouTubers' appearance and fashion style as individuality

- Partial recombination of YouTubers' fashion style or appearance management behaviour in everyday life

- Covering complex appearances or body shapes (makeup, change of body shape using fashion items)

- Eager to improve current appearance (increased interest in cosmetic surgery or procedure, beauty massage, diet pill)

- Exploring and sharing new fashion styles on YouTube algorithm (new fashion brand, item, searching for review contents)

- Desire to be distinguished from others (in real life) using fashion items 
emotional link or attachment with the brand or influencer (Muret, 2019).

As a result, the degree of trust in these cases differed for each research participant. Some reported that they generally trust the products YouTubers introduce and agree with their opinions. However, others replied that they do not trust them and that they need proper and critical perspectives, because it is now common for fashion YouTubers to obtain sponsorship of a product and produce promotional videos similar to those on TV, which was not the case in the early days of the YouTubers' career. They tend to be wary of anything that is doubtful and are curious about whether their information is 'fact from experience' or 'intended advertisement'. This indicates that even though Generation $\mathrm{Z}$ is more influenced by YouTubers than by traditional celebrities, they rely only on what they have experienced, not on unnatural advertisements by YouTubers.

As for dress, I only believe a thing seen in a video objectively, like finishing. No matter how much I like fashion YouTubers, I believe only what I see (D, Middle school student, 15 years old).

Virtual bonds with fashion YouTubers. Most of the research participants reported that the friendly explanation and natural communication of YouTubers were helpful in forming virtual bonds with them. The YouTubers are usually of a similar age to viewers, have similar personal stories and make content based on their similar lifestyles.

However, some participants seemed to be uncomfortable with having deep relationships with them. Generation $\mathrm{Z}$ prefers distance from others and share their tastes and interests without causing any discomfort to others. This result supports the assumption that Generation $\mathrm{Z}$ prioritises privacy over collective interest in human relations.

I don't want to make friends with them because it can be a violation of their privacy. I want to leave my favourite one in a video as he is (A, Middle school student, 14 years old).

Effects of YouTube fashion content on perception of looks. The interviewees actively searched for content regarding their looks, including topics such as plastic surgery, makeup, body care and fashion styles. This had a variety of effects on their perception of how they look and their appearance management behaviour.

Formation of an ideal body image and increased surveillance of self. Previous studies have found that Generation Z's social media activities can lead to dissatisfaction with their looks (Fardouly and Vartanian, 2015; Tamplin et al., 2018) and how others on social media make them view their looks in a negative light. In other words, their upward comparisons of body images with those of fashion YouTubers lead to dissatisfaction with their looks. This corresponds with previous research findings that users on social media actively interpret and share a lot of information (Haferkamp et al., 2012), compare how they look with the highly visual images of ideal women on media (Ridgway and Clayton, 2016), and that this comparison on social media increased dissatisfaction with their looks (Fardouly and Vartanian, 2015).

Similar to prior research, the participants showed a lot of interest in theirs and others' appearances and expressed specific recognition of their looks or body size, improving and maintaining these factors according to their level of satisfaction with their appearance. This revealed that participants who are unsatisfied with their looks watched YouTube fashion videos as a means of collecting information to mitigate their complex.
Videos seem to have skinny people only. I don't have any feeling about plump ones, but only skinny and pretty girls stand out. Specifically, seeing the legs of YouTubers in the videos, I think I'll be able to wear the skinny jeans they are wearing only when I lose weight.

\section{(I, High school student, 17 years old)}

Things I thought as trivial seem to be a little important. For instance, YouTubers have fair skin and when I see mine, I say, 'Ah, suddenly I want to remove my pimples.'

\section{(F, High school student, 16 years old)}

Their high interest in looks and specific fashion tastes lead to constant and habitual watching of YouTube fashion videos and this has influenced how they perceive their bodies. They used negative words/expressions like 'inferior appearance', 'fat/chubby body', 'gave up on improvement of my appearance' and 'everyone is beautiful except me' to highlight unsatisfactory self-perceptions of how they look. The participants mentioned that the lost their selfesteem or self-respect after watching fashion-related content. This proves that YouTube fashion videos may have numerous emotional effects on viewers' perception of their looks. For example, a viewer watched a fashion video by a YouTuber who had similar eyes, skin colour and facial shape and heard the YouTuber say that she had a complex. In this case, the viewer would interpret her looks negatively regardless of whether it is true and might develop a desire for plastic surgery. When a YouTuber delivers professional information in a friendly manner, viewers are immersed in the role as both fan and friend and form one-sided bonds with the influencer. As a result, the viewers expressed their body dissatisfaction similar to that of comparing peers with themselves in everyday life. Although this is a virtual relationship, viewers can still feel the bond and it makes appearance-related social comparison easy.

I'd been satisfied with my eyes but my favourite YouTuber resembling me said it was her weak point. I liked rounded eyes but she said it was a complex. So, I thought 'Ah, the Mongolian fold is not good.' I want to have an epicanthic surgery, as soon as possible.

\section{(H, High school student, 17 years old)}

You know, I didn't have any dissatisfaction with my legs but I came to have a complex about them while seeing fashion YouTubers with very long and pretty legs.

\section{(B, Middle school student, 14 years old)}

Acceptance of the diverse face/body shapes and lowering of ideal beauty standards. There were cases where viewers came to perceive people with different looks, body types and fashion tastes that they met on YouTube as having their own individuality, unlike on TV, and thus gained confidence in their own looks. They reported that YouTubers were unique and attractive when they put on makeup that differentiated them from others or wore a fashion style that fit their body type, even if the body does not meet the typical conditions for beauty in Korea, including a skinny body, an egg-shaped face, eyes with double eyelids and a high and natural nose like those of TV celebrities (Lee, 2019c). Therefore, rather than accepting stereotypes such as a skinny body and a face with perfect proportions as pushed by traditional media, some Generation $Z$ recognised the diversity of looks through YouTube, regained confidence in their looks and thought 
of their body image more positively. This demonstrates that the high standards of ideal beauty presented by traditional media are being changed, and that Generation $\mathrm{Z}$ emphasises individual beauty and personality as well as the unique attraction of YouTubers.

However, despite recognising and accepting how diverse looks can be, some of the participants still gave contradictory opinions, saying there is no change in the standards for ideal beauty in the society to which they belong. Hence, they need skin or body care and have to lose weight. This reflects how deeply lookism, which places emphasis on external appearance, has been rooted in our society in the last few decades.

It's not that there are only slim persons on YouTube. There are small and tall YouTubers and plump and skinny YouTubers. Seeing all of them, I think 'Should I really lose weight, or maybe I can try this on, such as a stylish dress.'

$(\mathrm{N}$, College student, 23 years old)

Enhancement of the tendency to pursue individuality. Participants who rejected conformity to the ideal body and face and recognised the diversity of looks took time to pick fashion styles that highlighted their individuality and physical attraction. In answer to questions about wearing fashion brand products that popular with their peers, they said 'I don't like it maybe because I can lose $m y$ individuality,' and 'My favourite is everything no matter what they wear', showing a strong desire to express themselves through clothing. Generation $\mathrm{Z}$ has different tendencies from that of prior generations. Thus, fashion YouTubers should respect their taste and encourage them to explore their individuality.

I think I have to pursue my own individuality when I get dressed. So, I think I have to find unique things different compared to others when buying clothes at shops near Gangnam Station.

\section{(B, Middle school student, 14 years old)}

There appear many unique people on YouTube, so I came to know that even strange-looking persons can dress up considering their individuality. Therefore, I apply styles partially while watching YouTube videos. (H, High school student, 17 years old)

Effects of YouTube fashion content on appearance management behaviour. Continued viewing of YouTube fashion videos influences not only Generation Z's perception of looks but also their practical appearance management behaviour, including direct changes of their faces and bodies as well as their clothing behaviour.

Immediate copying of appearance management based on concrete information. Some participants watch videos of fashion YouTubers who look like themselves to handle their appearance complex. They apply detailed information about makeup and skin care on YouTube to their everyday lives. In addition, after watching videos that show the evolution from bare faces to faces with makeup, they conclude that there is no need for plastic surgery. They believe they should accept how they look and showed more interest in makeover videos and fashion goods that complement their body type, especially YouTube videos that introduce relatively low-priced makeup or apparel products. If the brand receives favourable responses from viewers, the consumers will purchase and use it, which will, in turn, boost their satisfaction with their looks. Information about makeup, cosmetics, plastic surgeries and fashion styles that are provided by YouTubers are compiled and imitated. The responses below show that YouTube celebrities have great influence on the daily appearance management of Generation Z.

I see and copy almost everything, like face shading, putting on a high lighter and an eye liner and cutting side hair to cover parts without hair. I also learn how to cover my jaw line or cheekbone.

\section{(K, High school student, 18 years old)}

Videos about a plastic surgery show pain frankly but I want to do it because they are so pretty after surgery. Everything is possible if you can have plastic surgery. I mean nose and double-eyelid surgeries. I made a plan with my friend.

(A, Middle school student, 14 years old)

Search for fashion goods reflecting the taste and application of fashion style. Fashion YouTubers do not only upload videos that recommend fashion products. They also produce lifestyle videos that attract viewers' attention or reflect their specific tastes. Examples include Coordination for Youth School Trip, Recommended Fashion for Cute College Students and Recommended Cost-Effective Brand. This shows that Generation $\mathrm{Z}$ watch review or product comparison videos on YouTube based on the algorithm function before purchasing goods and thus lower the risk associated with online purchases like not being able to wear or use a product beforehand, or searching for an optimal alternative that fits their desired style.

By the way, I don't like to wear a brand which others put on. They have the same taste. I don't care about brands so I buy and wear something before it is in vogue after watching a fashion YouTube video.

(F, High school student, 16 years old)

\section{Discussion}

This study aimed to ascertain the influence of YouTube fashion content on female Generation Z through in-depth interviews of 15 of them. The research findings are discussed below.

First, the Generation $\mathrm{Z}$ research participants consumed a lot YouTube videos daily. They believe that their pursuit of fun and information on YouTube is an important part of their daily life. They watch YouTube fashion videos on their smartphones and their particular favourites are videos on introduction and unboxing of particular fashion goods, fashion coordination and reviews of fashion items. Generation $\mathrm{Z}$ considers YouTube a medium for leisure. In particular, they were grouped around specific fashion YouTubers who they have great affection, through activities such as asking or sharing information, expressing their opinions and having virtual communications with others. Moreover, Generation Z selects what they watch and what influencer they follow based on personal fashion/beauty tastes. They sometimes feel more in tune with YouTubers who share information in a friendly manner than with famous TV celebrities. The participants view YouTubers as attractive and have a desire to imitate their internal aspects as well, including their character, attitude and values.

Second, the replies given by the research participants provided the different ways they view YouTubers, from informants, to trustees and influencers. Most of all, they were more influenced 
by YouTube celebrities than by famous celebrities on TV or magazines because YouTube celebrities had an ideal image, their own unique charm and a taste similar to theirs. They feel friendlier towards YouTubers because they have lived life in an environment similar to theirs and provide information they can easily copy. Previous studies on Generation $\mathrm{Z}$ state that they are characterised by scepticism and avoiding unnecessary relationships, even though they are influenced more by influencers than traditional celebrities (Singh and Dangmei, 2016; Na, 2018). They have a dual image when forming stable relations with others (Chicca and Shellenbarger, 2018), which manifests in their neutral attitudes when accepting information provided by YouTubers, in their fact-checking their experiences and also in their rejection of face-to-face relationships with YouTubers. When it comes to accepting fashion-related information from influencers such as recommendations, styling, product review, they reject conformity to the ideal style and pursue their own individuality. This tendency is a Generation $\mathrm{Z}$ characteristic that explains teenagers' sense of belonging when they wear clothes worn by their peers, as they have no firm fashion tastes (Kang, 1974) and gain psychological stability by wearing name-brand products to express an image similar to the group to which they belong (Kim, 1975).

Third, Generation Z's perception of looks in various media is influenced by YouTube videos. Similar to earlier research on increased dissatisfaction levels with their bodies in young women after using tradition media (Bell and Dittmar, 2011), or participating in social media activity (Fardouly and Vartanian, 2015; Djafarova and Rushworth, 2017; Tamplin et al., 2018), participants formed subjective body images while comparing their looks with those of YouTubers and expressed dissatisfaction with how they (participants) look. This result supports findings in previous research that viewers who imitate fashion and makeup tips given by YouTubers with the ideal body type are eventually influenced to change their lifestyle (Kim et al., 2018). In particular, one-way bonds and familiarity with YouTubers who have the ideal body (Grabe et al., 2008) or live a similar lifestyle make it easier for viewers to build a consensus formation (Abidin, 2016). This shows that social comparisons of physical appearance or body dissatisfaction in Generation $\mathrm{Z}$ can be affected by YouTube in a similar pattern as friends in face-to-face interactions.

Fourth, Generation $\mathrm{Z}$ is very curious about the fashion goods introduced by fashion YouTubers and actively use YouTube as a source of appearance management tips. They watch and immediately copy videos with titles like 'Makeup Process', 'Advice on Skin Care', 'Fashion Coordination Methods' and 'Body Care Methods' made by fashion YouTubers. When a product fits their taste, it leads to actual consumption, which boosts their appearance. Relatively inexpensive products for everyday life that are sui for their age and consumption level are introduced in these videos, and this stimulates their desire to consume that product. As a result, Generation $\mathrm{Z}$ women pursue improved external images under the influence of YouTubers and actively purchase and use certain products. These findings correspond with to those from other studies, which found that social media use exposed viewers to ideal body images and led to comparisons and their copying others' appearance management methods (Djafarova and Rushworth, 2017; Kim et al., 2018).

\section{Conclusion}

Generation $\mathrm{Z}$ consumes various fashion YouTube videos using their mobile devices, actively express their opinions and share information with others. This shows that while the older generation passively receive information about trends and fashion goods from traditional media, including $\mathrm{TV}$, magazines and specialised books, Generation Z uses YouTube as a type of fashion media and quickly acquires a variety of information about fashion, including appearance management, style and trends. Furthermore, Generation $\mathrm{Z}$ conducts comparative analysis of information they desire out of the flood they access on their mobile devices. Even when they have a favourable attitude towards the fashion YouTubers they watch, Generation $\mathrm{Z}$ is sometimes sceptical about some of the information on appearance management they provide and has limited relationships with them based on their own clear standards of relations with others.

Generation $\mathrm{Z}$ has become very interested in the appearance management behaviour shown in the videos and the fashion brands and goods introduced by YouTubers. This has a variety of effects on their perception of how they look and appearance management behaviour, leading to their purchase of the advertised goods. They are constantly exposed to appearance management videos, and therefore, sometimes perceive their body image negatively or engage in upward comparisons with YouTubers. In conclusion, the fashion-related content on YouTube watched by Generation $Z$ has many effects on appearances: the acceptance of the diversity of beauty; the enhancement of the pursuit of individuality; the search for specific tastes and negative effects on their perception of how they look.

As such, Generation $\mathrm{Z}$ is greatly influenced by the words and actions of fashion YouTubers and by the visual stimuli they provide. Their information about products and appearance management are used as indexes of their lifestyles and consumption habits. Accordingly, their viewing of YouTube videos can be connected to the actual purchase of a product beyond fun or leisure, meaning that detailed marketing strategy research on their characteristics is needed. For instance, because Generation $\mathrm{Z}$ has favourable attitudes toward YouTubers, their close relationships with and loyalty to YouTubers may be used as marketing tools. Moreover, because Generation $\mathrm{Z}$ pursue their own personalities and are greatly interested in how they look, YouTube can grow as an independent fashion medium if it can read fashion trends fast.

This study examined the effect YouTube fashion content have on the perception and appearance management behaviour of female Generation $Z$ viewers. The study is expected enable better understanding of Generation $\mathrm{Z}$, not from quantitative values about social media use or consumption patterns, but from a context of voluntary YouTube watching experience. The study also identified the various effects two-way media have on perception of looks, going further than existing research that confirm that one-way media have effects on individual perception of looks. However, this study has some limitations. First, it examined only short-term YouTube watching experience between 1 and 2 years. Hence, a follow-up study is needed on what effect long-term YouTube watching has on individual perception of looks and appearance management behaviour. Second, these research findings cannot be generalised because the interviews were conducted with only a limited number of young Korean women who enjoyed watching fashion-related content. These results cannot be said that all persons in Generation $\mathrm{Z}$ watch YouTube or that fashion videos only negatively affect Generation Z's perception of appearance, even if their media usage rate is higher than the other generations. Thus, this study is not enough to represent all members of Generation Z. Therefore, the next study on the experience of young male viewers of YouTube content will be helpful in understanding their current media uses, media influence on self-perceptions and appearance management behaviour from different perspectives.

This study has implications for fashion marketing and media that target Generation Z. First, it is possible to enhance the image of a fashion brand or the persuasive power of a product if it uses 
YouTube celebrities for its marketing, because there is active communication between YouTube celebrities and Generation Z. Furthermore, Generation $\mathrm{Z}$ trusts the factual information provided by YouTubers. Here, indirect advertising strategies using YouTubers will be more appealing to Generation $\mathrm{Z}$ for product reliability and authenticity, rather than traditional celebrities. Furthermore, given that Generation $\mathrm{Z}$ is interested in funny or persuasive brands, story-based marketing with a unique character that allows consumers to have new experiences will appeal to them. Second, as shown in the research findings, fashionthemed videos are bringing about changes not only in the media use of Generation Z but also in their perception and behaviour related to appearance. Therefore, we should pay attention to the fact that YouTube video content emphasising an excessively skinny body or indiscreetly recommending cosmetic surgeries may promote lookism to viewers. In addition, it is necessary to have active discussions about the adequacy of introduced products and the regulation on advertisement. In conclusion, YouTubers who produce fashion video contents need to take the responsibility that they should produce videos with appropriate value standards for appearance considering the influence they have on viewers.

Ethical approval. This research was conducted in an ethical way, under the approval and supervision of Seoul National University Institutional Review Board (IRB No. 1903/001-009) regarding ethical issues in the whole research process.

\section{Data availability}

The datasets generated during and/or analysed during the current study are not publicly available due to confidentiality reasons, but are available in a codified form from the corresponding author on reasonable request.

Received: 21 February 2020; Accepted: 3 November 2020; Published online: 26 November 2020

\section{References}

Abidin C (2016) “Aren't these just young, rich women doing vain things online?": influencer selfies as subversive frivolity. Soc Media+Soc 1-17. https://doi.org/ $10.1177 / 2056305116641342$

Adecco (2015) Generation Z vs. millennials. Adecco. http://pages.adeccousa.com/rs/ 107-IXF-539/images/generation-Z-vs-millennials.pdf. Accessed May 12020

Freeman B, Chapman S (2007) Is "YouTube" telling or selling you something? Tobacco content on the YouTube video sharing website. Tobacco Control 16 (3):207-210. https://doi.org/10.1136/tc.2007.020024

Bell BT, Dittmar H (2011) Does media type matter? The role of identification in adolescent girls' media consumption and the impact of different thin-ideal media on body image. Sex Roles 65(8):478-490. https://doi.org/10.1007/ S11199-011-9964-X

Bennett J, Pitt M, Price S (2012) Understanding the impact of generational issues in the workplace. Facilities 30(7/8):278-288. https://doi.org/10.1108/ 02632771211220086

Berkup SB (2014) Working with generations $\mathrm{X}$ and $\mathrm{Y}$ in generation $\mathrm{Z}$ period: management of different generations in business life. Mediterr J Soc Sci 5 (19):218-229. https://doi.org/10.5901/mjss.2014.v5n19p218

Berry KA, Kowalski KC, Ferguson LJ, McHugh TLF (2010) An empirical phenomenology of young adult women exercisers' body self-compassion. Qual Res Sport Exerc 2(3):293-312. https://doi.org/10.1080/19398441.2010.517035

Bolser K, Gosciej R (2015) Millennials: multi-generational leaders staying connected. J Pract Consult 5(2):1-9

Byun $\mathrm{H}$ (2018) Analyzes the characteristics in the contents production and usage environment of YouTube and its popular channels; and examination of its implications. Treatise Plast Media 21(4):227-239

Chicca J, Shellenbarger T (2018) Connecting with Generation Z: approaches in nursing education. Teach Learn Nurs 13(3):180-184. https://doi.org/10.1016/ j.teln.2018.03.008
Choi GY, Behm-Morawitz E (2017) Giving a new makeover to STEAM: establishing YouTube beauty gurus as digital literacy educators through messages and effects on viewers. Comput Hum Behav 73:80-91. https://doi.org/ 10.1016/j.chb.2017.03.034

Daehaknaeil20slab (2018) Trend MZ 2019. Hanbit Biz, Seoul

Djafarova E, Rushworth C (2017) Exploring the credibility of online celebrities' Instagram profiles in influencing the purchase decisions of young female users. Comput Hum Behav 68:1-7. https://doi.org/10.1016/j.chb.2016.11.009

Fardouly J, Vartanian LR (2015) Negative comparisons about one's appearance mediate the relationship between facebook uses and body image concern. Body Image 12:82-88. https://doi.org/10.1016/j.bodyim.2014.10.004

Giorgi A (1994) A phenomenological perspective on certain qualitative research methods. J Phenomenol Psychol 25(2):190-220

Gladwell M (2000) The tipping point: how little things can make a big difference. Little Brown, New York

Grabe S, Ward LM, Hyde JS (2008) The role of the media in body image concerns among women: a meta-analysis of experimental and correlational studies Psychol Bull 134(3):460-476. https://doi.org/10.1037/0033-2909.134.3.460

Haferkamp N, Eimler SC, Papadakis AM, Kruck JV (2012) Men are from mars, women are from venus? Examining gender differences in self-presentation on social networking sites. Cyberpsychol Behav Soc Netw 15(2):91-98. https:// doi.org/10.1089/cyber.2011.0151

Hasnan L (2019) Gen Z's use of social media has evolved. The ASEAN Post. https://theaseanpost.com/article/gen-zs-use-social-media-has-evolved. Accessed 25 Dec 2019

Herold DK (2008) Development of a civic society online?: internet vigilantism and state Control in Chinese Cyberspace Asia J Global Stud 2(1):26-37. http:// hdl.handle.net/10397/4434

Jensen JF, Petersen MH, Tine, Larsen TB, Jørgensen DG, Grønbæk HN, Midtgaard J (2014) Young adult women's experiences of body image after bariatric surgery: a descriptive phenomenological study. J Adv Nurs 70(5):1138-1149. https://doi.org/10.1111/jan.12275

Kang HW (1974) A study on the relationship between attribute and attribute of attribute to individuality and fashion of university students. Fam Environ Res 12(3):774-775

Kemper G (2019) What marketers need to know about Gen Z social media habits. Business 2 Community. https://www.business2community.com/social-media/ what-marketers-need-to-know-about-gen-z-social-media-habits-02222668. Accessed 20 Oct 2019

Keum HJ (2006) The influences of entertainment television use on social comparison and life satisfaction-focusing on individuals' economic situations and romantic relationships. Korean J Broadcast Telecommun Stud 21(2):98-137

Kim BM (1975) Research: a study on the clothing behaviour of adolescents. Fam Environ Res 13(3):233-247

Kim JR, Kang SM, Lee, KH (2018) How social capital impacts the purchase intention of sustainable fashion products. J Bus Res 1-8. https://doi.org/ 10.1016/j.jbusres.2018.10.010

Kim YC, Jung SW (2017) Data analysis. Academy Press, Paju

Lee HS (2019a) "What kind of YouTuber do you think has the highest income by field?". The Outsourcing Times. http://www.outsourcing.co.kr/news/ articleView.html?idxno=84889. Accessed 30 Dec 2019

Lee SJ (2019b) When Generation Z are alone, 79.7\% watching 'video contents'. Cosmetic Insight. https://www.cosinkorea.com/news/article.html?no=33090. Accessed 22 Dec 2019

Lee HG (2019c) Face type is Kim Tae Hee, and nose is Han Ga Eun... Koreans prefer three-dimensional beauty. PharmNews. http://www.pharmnews.com/ news/articleView.html?idxno=99266. Accessed 22 Dec 2019

Lee JE, Watkins B (2016) YouTube vloggers' influence on consumer luxury brand perceptions and intentions. J Bus Res 69(12):5753-5760. https://doi.org/ 10.1016/j.jbusres.2016.04.171

Lidija PI, Kiril P, Kiril P, Ilive AJ, Shopova MM (2017) Establishing balance between professional and private life of generation Z. Res Phys Educ Sport Health 6(1):3-9

Linkletter M, Gordon K, Dooley J (2010) The choking game and YouTube: a dangerous combination. Clin Pediatr 49(3):274-279. https://doi.org/10.1177/ 0009922809339203

Lorgulescu MC (2016) Generation Z and its perception of work. Cross-Cult Manag J 1:47-54

Lypnytska O (2019) Marketing to Generation Z: 11 important things to keep in mind. PUSHPUSH. https://pushpushgo.com/en/blog/marketing-togeneration-z/. Accessed 10 Jan 2020

Meier EP, Gray J (2014) Facebook photo activity associated with body image disturbance in adolescent girls. Cyber Psychol Behav Soc Netw 17 (4):199-206. https://doi.org/10.1089/cyber.2013.0305

Morton LP (2002) Targeting generation Y. Public Relations Q 47(2):16-26

Mullen C (2019) Almost 1 in 4 Gen Z women typically learn about new products via influencers. Bizwomen. https://www.bizjournals.com/bizwomen/news/ 
latest-news/2019/11/almost-1-in-4-gen-z-women-typically-learn-about.html? page $=$ all. Accessed 10 Jan 2020

Muret D (2019) Gen Z is over celebrity glitz; wants transparency and authenticity. Fashion Network. https://us.fashionnetwork.com/news/Gen-z-is-over-celebrityglitz-wants-transparency-and-authenticity,1150680 html. Accessed 14 Aug 2020

Myers TA, Crowther JH (2009) Social comparison as a predictor of body dissatisfaction: a meta-analytic review. J Abnormal Psychol 118(4):683-698. https://doi.org/10.1037/a0016763683

Na YS (2018) X-Y-Z Change of new generation. Sedaily. https://www.sedaily.com/ NewsView/1S5VW1AR6X. Accessed 10 Jan 2020

Ozkan M, Solmaz B (2015) Mobile addiction of Generation Z and its effects on their social lifes: (an application among university students in the 18-23 age group). Procedia-Soc Behav Sci 205(9):92-98. https://doi.org/10.1016/j. sbspro.2015.09.027

Park JY (2019) A study on mobile video usage of Generation Z in the Republic of Korea based on the grounded theory-focused on Youtube. Unpublished master's thesis, Hongik University, Seoul

Park SG (2017) An exploratory study on shopping orientation, clothing consumption value and purchase decision making process among generation $\mathrm{Z}$ females. Unpublished mster's thesis, Yonsei University, Seoul

Pastore A (2020) After pay retail partners see basket size grow year-over-year. WWD. https://wwd.com/business-news/business-features/afterpay-retailpartners-holiday-2019-shopping-12. Accessed 10 Jan 2020

Paton E, Lorenz T, Kwai I (2019) What do Gen Z shoppers want? A cute, cheap outfit that looks great on instagram. N Y Times. https://www.nytimes.com/ 2019/12/17/style/fast-fashion-gen-z.html. Accessed 10 Jan 2020

Patrick H, Neighbor C, Raymond knee C (2004) Appearance-related social comparisons: the role of contingent self-esteem and self-perceptions of attractiveness. Personal Soc Psychol Bull 30(4):501-514. https://doi.org/10.1177/ 0146167203261891

Perloff RM (2014) Social media effects on young women's body image concerns: theoretical perspectives and an agenda for research. Sex Roles 71:363-377. https://doi.org/10.1007/s11199-014-0384-6

PR Newswire (2019) YouTube gaining popularity with Generation $Z$ as demand for video content rises, Facebook's popularity declining. Yahoo!finance. https:// finance.yahoo.com/news/youtube-gaining-popularity-generation-z124200385.html. Accessed 11 Jan 2020

Priporas CV, Stylos N, Fotiadia AK (2017) Generation Z consumers' expectations of interactions in smarter tailing: a future agenda. Comput Hum Behav 77:374-381. https://doi.org/10.1016/j.chb.2017.01.058

Ridgway JL, Clayton RB (2016) Instagram unfiltered: exploring associations of body image satisfaction, Instagram \#Selfie Posting, and negative romantic relationship outcomes. Cyberpsychol Behav Soc Netw 19(1):2-7. https://doi. org/10.1089/cyber.2015.0433

Ryan MS (1966) Clothing: a study in human Behaviour. Holt, Hart and Winston, Inc, New York

Seok SH, Cho SN (2016) Celebrity use motivation and the formation of social identity among SNS users. Ewha J Soc Sci 32(1):119-158. https://doi.org/ $10.1089 / \mathrm{cpb} .2007 .0056$

Singh AP, Dangmei J (2016) Understanding the Generation Z: the future workforce. South-Asian J Multidiscipl Stud 3(3):1-5

Snoböhm C, Friedrichsen M, Heiwe S (2010) Experiencing one's body after a diagnosis of cancer-a phenomenological study of young adults. PsychoOncology 19:863-869. https://doi.org/10.1002/pon.1632

Southgate D (2017) The emergence of Generation $Z$ and its impact in advertising. J Advert Res 57(2):227-235. https://doi.org/10.2501/JAR-2017-028

Stefanone MA, Lackaff D, Rosen D (2010) The relationship between traditional mass media and 'social media': reality television as a model for social network site behavior. J Broadcast Electron Media 54(3):508-525

Stever GS, Lawson K (2013) Twitter as a way for celebrities to communicate with fans: Implications for the study of para-social interaction. N Am J Psychol 15 (2):339-354
Tang Q, Gu B, Whinston A (2012) Content contribution in social media: the case of YouTube. Paper presented at the 45th annual Hawaii international conference on system sciences, Hawaii, 4-7 January 2012

Tamplin NC, McLean SA, Paxton SJ (2018) Social media literacy protects against the negative impact of exposure to appearance ideal social media images in young adult women but not men. Body Image 26:29-37. https://doi.org/ 10.1016/j.bodyim.2018.05.003

Tiggemann M, Zinoviev K (2019) The effect of enhancement-free Instagram images and hashtags on women's body image. Body Image 31:131-138. https://doi.org/10.1016/j.bodyim.2019.09.004

Tran GA, Strutton D (2014) Has reality television come of age as a promotional platform? Modeling the endorsement effectiveness of celebreality and reality stars. Psychol Mark 31(4):294-305

Veirman MD, Cauberghe V, Hudders L (2017) Marketing through Instagram influencers: the impact of number of followers and product divergence on brand attitude. Int J Advert 36(5):798-828. https://doi.org/10.1080/ 02650487.2017.1348035

Wiedman KP, Hennings N, Langner S (2010) Spreading the word of fashion: identifying social influencers in fashion marketing. J Global Fashion Mark 1 (3):142-153. https://doi.org/10.1080/20932685.2010.10593066

Wiedmer T (2015) Generations do differ: best practices in leading traditionalists, boomers, and generations X, Y, and Z. Delta Kappa Gamma 82(1):51-58

Wiley D (2014) Why brands should turn to bloggers instead of celebrity spokespeople. Mark Land. http://marketingland.com/brands-turn-bloggers-insteadcelebrity-spokespeople-75971. Accessed 1 May 2020

\section{Author contributions}

JP designed research. In interviews with Generation Z, she collected and analysed the data and drafted the paper. JC suggested the direction and overall framework of the research and participated in the discussion of the research and the analysis of the data

\section{Competing interests}

The authors declare no competing interests.

\section{Additional information}

Correspondence and requests for materials should be addressed to J.C.

Reprints and permission information is available at http://www.nature.com/reprints

Publisher's note Springer Nature remains neutral with regard to jurisdictional claims in published maps and institutional affiliations.

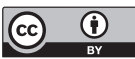

Open Access This article is licensed under a Creative Commons Attribution 4.0 International License, which permits use, sharing, adaptation, distribution and reproduction in any medium or format, as long as you give appropriate credit to the original author(s) and the source, provide a link to the Creative Commons license, and indicate if changes were made. The images or other third party material in this article are included in the article's Creative Commons license, unless indicated otherwise in a credit line to the material. If material is not included in the article's Creative Commons license and your intended use is not permitted by statutory regulation or exceeds the permitted use, you will need to obtain permission directly from the copyright holder. To view a copy of this license, visit http://creativecommons.org/ licenses/by/4.0/.

(C) The Author(s) 2020 